University of Wollongong

Research Online

Faculty of Health and Behavioural Sciences -

Papers (Archive)

Faculty of Science, Medicine and Health

June 2005

\title{
Breakfast and the diets of Australian adults: An analysis of data from the 1995 National Nutrition Survey
}

P. G. Williams

University of Wollongong, peterw@uow.edu.au

Follow this and additional works at: https://ro.uow.edu.au/hbspapers

Part of the Arts and Humanities Commons, Life Sciences Commons, Medicine and Health Sciences Commons, and the Social and Behavioral Sciences Commons

\section{Recommended Citation}

Williams, P. G.: Breakfast and the diets of Australian adults: An analysis of data from the 1995 National Nutrition Survey 2005.

https://ro.uow.edu.au/hbspapers/7

Research Online is the open access institutional repository for the University of Wollongong. For further information contact the UOW Library: research-pubs@uow.edu.au 


\title{
Breakfast and the diets of Australian adults: An analysis of data from the 1995 National Nutrition Survey
}

\author{
Abstract \\ The aim of this study was to describe the nutrients provided to Australian adults by the breakfast meal \\ and compare the food and nutrient intakes and health of regular breakfast eaters and skippers. The \\ Australian Bureau of Statistics was commissioned to undertake additional analysis of data collected in \\ the 1995 Australian National Nutrition Survey (NNS). The survey included 24 hour recalls, physical \\ measurements and a food habits questionnaire collected during the period February 1995 to March 1996, \\ with a nationally representative sample of 10851 Australians aged nineteen years and older. The median \\ nutrient intakes at breakfast and the proportion of the daily total contributed by breakfast were \\ calculated. Differences between regular breakfast eaters and breakfast skippers in terms of nutrient \\ intake, BMI and health status were compared using student t-tests. The findings show typical Australian \\ breakfast was low in fat, high in carbohydrate and a good source of thiamin, riboflavin, niacin, calcium and \\ magnesium. In the NNS regular breakfast eaters had more adequate diets overall, particularly those aged \\ $65+$ years. People who didn't eat breakfast cereal were much more likely to have inadequate nutrient \\ intakes, especially of thiamin, riboflavin, calcium, magnesium and iron. Regular breakfast eaters were \\ more likely to rate their health as excellent or good than those who skip breakfast, but there was no \\ difference between the fat intake or the BMI of regular breakfast eaters compared to breakfast skippers. \\ Regular breakfast consumption is associated with better diets for adults overall.
}

\section{Keywords}

breakfast; national nutrition survey, breakfast cereals, dietary intake

\section{Disciplines}

Arts and Humanities | Life Sciences | Medicine and Health Sciences | Social and Behavioral Sciences

\section{Publication Details}

This article was originally published as Williams, PG, Breakfast and the diets of Australian adults: An analysis of data from the 1995 National Nutrition Survey, International Journal of Food Sciences and Nutrition, 56(1), 2005, 65-79. Copyright Taylor \& Francis 2005. Original journal available here. 
Title: Breakfast and the diets of Australian adults: an analysis of data from the 1995 National Nutrition Survey

Author: $\quad$ Peter Williams ${ }^{\dagger}$

BSc(Hons) DipNutrDiet MHP PhD APD

${ }^{\dagger}$ The author planned and commissioned these analyses when previously employed as Director of Scientific and Consumer Affairs at Kellogg (Aust) Pty Ltd.

Current

Position: $\quad$ Senior Lecturer, Nutrition and Dietetics

Address: $\quad$ Department of Biomedical Science

University of Wollongong

NSW Australia 2522

Tel: $\quad 61242214085$

FAX: $\quad 61242214844$

e-mail peter_williams@uow.edu.au

Short Title: Breakfast nutrition

Key words: breakfast; national nutrition survey; breakfast cereals; dietary intake

Word Count: 3000

Version: IJFSN-V2 


\section{Breakfast and the diets of Australian adults: an analysis of data from the 1995 National Nutrition Survey}

\section{Summary}

The aim of this study was to describe the nutrients provided to Australian adults by the breakfast meal and compare the food and nutrient intakes and health of regular breakfast eaters and skippers. The Australian Bureau of Statistics was commissioned to undertake additional analysis of data collected in the 1995 Australian National Nutrition Survey (NNS). The survey included 24 hour recalls, physical measurements and a food habits questionnaire collected during the period February 1995 to March 1996, with a nationally representative sample of 10851 Australians aged nineteen years and older. The median nutrient intakes at breakfast and the proportion of the daily total contributed by breakfast were calculated. Differences between regular breakfast eaters and breakfast skippers in terms of nutrient intake, BMI and health status were compared using student t-tests. The findings show typical Australian breakfast was low in fat, high in carbohydrate and a good source of thiamin, riboflavin, niacin, calcium and magnesium. In the NNS regular breakfast eaters had more adequate diets overall, particularly those aged 65+ years. People who didn't eat breakfast cereal were much more likely to have inadequate nutrient intakes, especially of thiamin, riboflavin, calcium, magnesium and iron. Regular breakfast eaters were more likely to rate their health as excellent or good than those who skip breakfast, but there was no difference between the fat intake or the BMI of regular breakfast eaters compared to breakfast skippers. Regular breakfast consumption is associated with better diets for adults overall. 


\section{Introduction}

A number of reviews have emphasised the importance of breakfast for overall good nutrition (Chao \& Vanderkooy, 1989; Ruxton \& Kirk, 1997). It has been reported that intakes of vitamins and minerals missed when breakfast is skipped are not fully compensated during the rest of the day (Morgan et al, 1986; Zabik, 1987; Morg an et al., 1996; Reger et al, 1997; Preziosi et al, 1999) . Data from France indicate that high-energy breakfasts and cereal consumption are associated with lower cholesterol levels and improved serum concentrations of riboflavin and carotene in adults (Preziosi et al., 1999). The NHANES II survey in the US showed serum cholesterol levels were lowest among adults eating a breakfast that included ready-to-eat cereal (RTEC) and highest among breakfast skippers (Stanton \& Keast, 1989). Regular breakfast consumption has been identified as one of seven health practices associated with better health and reduced mortality in the elderly (Belloc \& Breslow, 1972; Kaplan et al, 1987) and newer research has also suggested that there may be benefits from breakfast consumption on general mood and mental performance (Michaud et al, 1991; Kanarek, 1997; Benton \& Parker, 1998; Smith, 1998; Smith, 1999).

However in Australia - aside from one report on the nutritional influence of breakfast cereal usage (Syrette et al, 1990) - there have been no studies describing the contribution of breakfast to adult dietary intakes or comparing the nutrient intakes and health of people who eat breakfast regularly versus those who do not.

The National Nutrition Survey (NNS), conducted jointly by the Commonwealth Department of Health and Family Services and the Australian Bureau of Statistics (ABS) during the period February 1995 to March 1996, provided an opportunity to examine this topic with comprehensive national data. Detailed results of the NNS have recently been published (McLennan \& Podger, 1997; McLennan \& Podger, 1998; McLennan \& Podger, 1999), however those reports do not describe the contribution of individual meals to daily nutrient intakes. Kellogg (Aust) commissioned the ABS to analyse the data from the NNS in relation to breakfast dietary patterns. Results about the foods consumed at breakfast 
and the prevalence of breakfast eating have been published (Williams, 2002) and a preliminary summary of results about nutrient intakes have been presented elsewhere (Williams, 1998). This paper reports the detailed findings from this analysis of the contribution of the breakfast meal to the nutrient intake of adult Australians (aged 19+ years) as well as some data on the relationship between breakfast consumption and health outcomes. 


\section{Method}

Kellogg (Aust) commissioned the ABS to analyse data collected in the NNS related to breakfast dietary patterns. The NNS covered a nationally representative sub-sample of the National Health Survey (NHS) and was conducted in the householders' homes by trained nutritionists. The primary method of dietary data collection was a 24-hour recall, hence the data indicate the intake of food items on the day prior to the interview, ie the day of recall. Physical measurements were taken of height, weight, waist and hip circumference and blood pressure. The response rate among those selected from the NHS participants for the NNS sample was 61\%. The total sample consisted of 13858 people aged two years and over from urban and rural areas in all States and Territories, including 10851 individuals aged 19 years or older. Full details of the methodology and the sampling have been published (McLennan \& Podger, 1998).

As well as the 24-hour recall, two other approaches were used to collect data on food intake. A food frequency questionnaire was used to assess the intake of selected foods including nutrient supplements over the previous 12 months. In addition, a series of questions was asked, including self reported health status on a five-point scale and "How many days per week do you usually have something to eat at breakfast?" Throughout this paper, those who indicated they ate breakfast five or more days a week are classified as regular breakfast "Eaters"; those who responded "rarely or never" are classified as breakfast "Skippers", which is the same definition used in other studies (Williams, 2002). In the 24-hour recalls, participants were asked to nominate the meal at which each food item was consumed, from a list of seven options which included breakfast. Therefore, the breakfast meal was self-defined by the participants, rather than being identified by the time of consumption or the type of food.

Nutrient intakes were calculated by staff of the ABS using the 24-hour recall data in the Confidential Unit Record File (CURF), which includes food intakes for each individual surveyed. A food composition database developed by the Australia New Zealand Food Authority was used to calculate nutrient intakes (Australia New Zealand Food 
Authority, 1999). Nutrient intakes at breakfast are presented as median rather than mean values because they were not normally distributed (McLennan \& Podger, 1998). Sodium intakes were not estimated in the NNS because of the unreliability of diet records for this purpose. Foods were categorised using the groupings of the NNS (McLennan \& Podger, 1998). Throughout this paper the category 'breakfast cereals' includes both cold ready-to-eat breakfast cereals (RTEC) and hot porridge-type cereals. The broad category 'cereal foods' includes breakfast cereals, breads, pastries, cakes and biscuits.

Food and nutrient intakes were compared with current recommended dietary intakes (RDI) for use in Australia (National Health and Medical Research Council, 1991) or other dietary target recommendations. The recommended target of $30 \mathrm{~g}$ dietary fibre per day for adults aged 19+ years was used (Better Health Commission, 1986). Serves of cereal foods were calculated by dividing the food intake in grams by the standard cereal serves defined by for the Australian Core Food Groups (Cashel \& Jeffreson, 1995): 30g for bread, $20 \mathrm{~g}$ for ready-to-eat-cereal, $90 \mathrm{~g}$ for cooked rice, pasta or porridge. Intakes were compared to the target of seven serves per day for adults aged 19+ years (Cashel \& Jeffreson, 1995). The dietary target of 55\% of energy from carbohydrate was taken from the recommendations of the FAO/WHO expert consultation on carbohydrates (World Health Organization, 1998).

The statistical significance of differences between breakfast Eaters and Skippers and between eaters and non-eaters of breakfast cereal were calculated using the Student ttest. 


\section{Results}

\section{The nutrients provided by breakfast}

The median nutrient intakes provided by the foods consumed at breakfast and the percentage this contributed to the total daily intakes are shown in Tables 1 and 2. For most nutrients the proportions were very similar for males and females, but the breakfast meal contributed a higher proportion of the total daily intake of older adults compared with the younger age groups. Table 3 shows the proportion of the recommended daily nutrient intakes provided by the foods consumed at the breakfast meal. Breakfast was generally a very nutritious meal. It was low in fat (24-28\% energy came from fat), high in carbohydrate (providing 56-59\% of energy), a significant source of dietary fibre, and rich in micronutrients.

Breakfast was a particularly good source of thiamin, riboflavin and calcium, contributing over $25 \%$ of the median daily intake of these nutrients for adults, while providing just $15 \%$ of the daily energy intake. Less than $10 \%$ of the median daily intakes of vitamins $\mathrm{A}$ and $\mathrm{C}$ were supplied at breakfast. The breakfast meal provided more than $25 \%$ of the recommended dietary intakes of all the micronutrients assessed except zinc and vitamin A.

Breakfast cereals, as consumed with milk and sugar, contributed significantly to the nutrient density of the breakfast meal. For adults they provided around $6 \%$ of the total daily energy intake, but were a good source (>25\% RDI) of thiamin, riboflavin and (for men) iron, and a source (>10\% RDI) of protein, niacin, folate (for men), calcium, iron (for women), magnesium and phosphorus. Breakfast cereals alone provided $12 \%$ of the dietary fibre, but only $3.5 \%$ of the sugar in the overall daily intake of adults - similar to the percentages reported in the US (Morgan et al, 1981) and England (Hackett et al, 1986). People over 65 years, who were the greatest users of bran cereals (Williams, 2002), obtained more than $15 \%$ of their dietary fibre from breakfast cereals. 


\section{Comparison of breakfast Eaters and Skippers}

\section{Nutrient intakes}

Tables 4 compares the mean daily nutrient intakes of Australian adult breakfast Eaters and Skippers. Clearly those who regularly ate breakfast had significantly better diets overall - higher in carbohydrate and dietary fibre and richer in almost all vitamins and minerals, especially thiamin, riboflavin, folate, calcium, iron and magnesium. There were no significant differences in the intakes of fat or sugar between breakfast Eaters and Skippers aged 19+ years.

For every nutrient, a significantly higher proportion Eaters than Skippers met the RDI or dietary target on the day of the survey (see Figures 1 and 2). These differences were particularly significant for thiamin, riboflavin, folate, calcium and magnesium, and also (for women only) iron. The differences were even greater for older adults, among whom the risk of an inadequate diet was significantly greater in breakfast Skippers. The proportion of Skippers in the oldest age groups consuming less than $70 \%$ of the RDI was more than twice that of breakfast Eaters for almost every nutrient, including protein.

\section{Dietary goals}

Adult breakfast Eaters also consumed significantly more serves of cereal foods in the day than the Skippers (males: 6.3 vs 3.4, p<0.001; females: 4.4 vs $2.8 ; \mathrm{p}<0.001$ ) and were more than twice as likely to meet the target for serves of cereal foods (Cashel \& Jeffreson, 1995) (28\% vs 14\%; p<0.001). Adult male (but not female) breakfast Eaters were also more likely than Skippers to meet the target of $>55 \%$ energy from carbohydrate $(18 \%$ vs $10 \%, \mathrm{p}<0.001)$. More Eaters met the dietary targets for fibre (Better Health Commission, 1986) than Skippers, especially in the oldest age groups (males aged 65+: $26.4 \%$ vs $5.4 \%, \mathrm{p}<0.001$; females aged $55+: 16.1 \%$ vs $2.1 \%$. $\mathrm{p}<0.001)$. 
Figure 3 compares the proportion of eaters and non-eaters of breakfast cereal who, on the day of the survey, did not achieve a daily intake of $70 \%$ of the RDI. For every nutrient, a higher proportion of breakfast cereal eaters had daily intakes above $70 \%$ of the RDI than did those who did not eat breakfast cereal. In addition women (but not men) over the age of 25 who included RTEC in their diets were also more likely to meet the dietary target of $30 \%$ energy from fat than those who did not eat breakfast cereal $(62 \%$ vs $54 \%$; $\mathrm{p}<0.05)$.

\section{Health status}

The limited data on health status collected in the NNS makes it difficult to examine the relationship between breakfast consumption and health outcomes directly from this data. However, two measurements were available and relevant: body mass index (BMI) and self-reported health status. Comparisons of the BMI of adult breakfast Eaters and Skippers found no significant difference between the two groups $(p=0.159)$.

Table 5 shows the proportion of Eaters and Skippers who rated their health as excellent, very good, good, fair or poor. Significantly more breakfast Eaters rated their health as excellent than did Skippers. There were no differences in the proportions rating their health as fair or poor. 


\section{Discussion}

The results of this analysis clearly show that breakfast consumption was associated with a more nutritious diet overall and one that was significantly more likely to meet recommended nutrient intakes, especially for thiamin, riboflavin, calcium, magnesium and iron. This supports similar conclusions from studies in the US, the UK and Ireland (Morgan et al, 1986; McNulty et al., 1994; Reger et al, 1997; Galvinet al, 2003) . In France it has been reported that adults consuming higher-energy breakfasts had higher daily intakes of vitamins and minerals than those eating smaller breakfasts (Preziosi et $a l ., 1999)$. The NNS found that older adults in Australia consumed larger breakfasts than younger adults (males $1574 \mathrm{~kJ}$ at ages $25-44$ vs $1843 \mathrm{~kJ}$ at $65+$; females $1154 \mathrm{~kJ}$ at ages $25-44$ vs $1303 \mathrm{~kJ}$ at $55+$ ) (Williams, 2002). This may be one reason that the positive impact of breakfast eating on overall nutrient intake appears even greater for older Australians.

The low median intake of vitamin $\mathrm{C}$ at breakfast reflects the highly skewed distribution of the nutrient intake. Only $17 \%$ of adults consumed any fruit or juice at breakfast in the NNS (Williams, 2002) so the median intakes of vitamin C were very low. The mean intakes at breakfast were higher (20.9mg for males; $18.3 \mathrm{mg}$ for females) which contributed $16 \%$ of the total intake, an equal proportion to the energy provided at the meal. Many RTEC are fortified with non-haem iron and claim to provide a good source of iron, but it may be questioned how bio-available this is likely to be for the majority of consumers who are not including a good source of vitamin $\mathrm{C}$ at their breakfast meal. Consequently it may be important for vitamin $\mathrm{C}$ to be included as a fortificant in these products, or to always promote their consumption in the context of a balanced breakfast, including fruit.

In other studies it has been reported that breakfast consumption is associated with a lower daily fat intake (MacDiarmid et al, 1997; Schmidt et al, 1998) and that an increased breakfast cereal consumption reduces the percentage of dietary energy from fat (Kirk et al, 1997). In this analysis women aged 25+ years who ate RTEC had a 
lower percentage of energy from fat, but there was no significant difference in the total daily fat intake nor the percentage of energy from fat between regular breakfast Eaters or Skippers overall. The reason for this may be that the level of fat in the diet of Australian adults $(32.4 \% \mathrm{E})$ was significantly lower than that reported in other studies in US or UK populations, so the impact of breakfast at a population level may be less easy to detect. Nonetheless, breakfast consumption could still be a useful intervention strategy for individuals since several controlled studies have shown that consumption of RTEC can lower assist in weight loss (Kirk et al, 1997; Mattes, 2002), and that breakfast-eating generally may be a factor in successful weight loss maintenance (Wyatt et al., 2002).

There was no association between regular breakfast consumption and BMI. Given that there was a higher energy intake in regular breakfast eaters, it is possible that the energy expenditure was also higher in this group, which suggests that there are likely to be lifestyle differences between breakfast eaters and skippers other than differences in dietary patterns. In the US and Finland an increase in BMI has been associated with a decreased likelihood of breakfast consumption in children (Siega-Riz et al, 1998; Keski-Rahkonen et al, 2003), but others have found no difference in the BMI of breakfast eaters and skippers amongst young adults (Huang et al, 1997) .

Consumption of breakfast cereals specifically appeared to be associated with a more nutrient dense total diet. This finding is consistent with those from two Irish studies, which reported that adults who were breakfast cereal eaters were more likely to have intakes that met British reference nutrient intakes (Sommerville \& O'Reagan, 1993; Galvin et al., 2003). It also supports the results of another Australian study analysing a smaller 1988 national survey of 2802 adults that concluded daily consumption of breakfast cereal could contribute markedly to the quality of the Australian diet (Syrette et al., 1990). Others have reported that breakfast cereals also contribute significantly to Australian trace element intakes and in this way could play an important role in ensuring a balanced diet (Wang et al., 1992). Recent analyses of data from the prospective US Physicians' Health Study found that both total and CVD-specific 
mortality were inversely associated with whole-grain breakfast cereal intake (Liu et al, 2003).

It should be noted that there have been some significant changes to the fortification of Australian breakfast cereals since the NNS was carried out. Since July 1996, folate fortification has been permitted and adopted in many popular RTEC products, so it is likely that the contribution of folate from breakfast cereals is significantly greater today than it was as the time of the NNS. A number of breakfast cereals also began being fortified with zinc (to 15\% RDI) in 1998. Furthermore, the permitted form of vitamin A for cereal fortification changed from retinol to beta-carotene only (Food Standards Australia New Zealand, 2002) and a number of RTEC products consequently had vitamin A removed as a fortificant in 1996. It is therefore probable that the NNS results from 1995/6 overestimate the current total vitamin A intakes and underestimate the folate and zinc intakes.

The results on self-reported health status are consistent with the findings of at least one other study of breakfast cereal consumption and subjective reports of health (Smith, 1999), but it is not possible to conclude from this relationship that breakfast eating causes better health. It may be that those who are careful to maintain good health also choose to consume breakfast regularly as part of a healthy lifestyle, or that poor health causes some people to skip breakfast more often (Keski-Rahkonen et al, 2003). The results presented here suggest an association between breakfast consumption and better diet quality and health, but to determine whether it is the effect of breakfast per so or other factors related to lifestyle would require a properly controlled clinical trial.

Given the results presented here, it is of concern that up to $40 \%$ of young Australian adults are now skipping breakfast regularly (McLennan \& Podger, 1997). The recent dietary guidelines for older Australians recommend eating at least three regular meals per day, including consumption of a balanced breakfast (National Health and Medical Research Council, 1999). The same advice may be just as relevant for younger adults and it could be useful as a general health promotion message for several reasons: 
- It is a positive message, encouraging people to eat foods they already enjoy rather than asking them to restrict their intake of less desirable alternatives

- It can be promoted as a practice that may bring positive benefits, not only to longterm nutritional health but also to mood and cognitive performance (Kanarek, 1997; Benton \& Parker, 1998; Smith, 1998).

- It is a simple strategy for improving the intake of some of the key at-risk nutrients in the food supply - calcium, iron, folate and dietary fibre

- It fits with the newly emerging philosophy of food-based dietary guidelines that is being promoted by the World Health Organisation (Clay, 1997). 


\section{Conclusions}

The typical Australian breakfast for adults is a very nutritious meal - high in carbohydrate and dietary fibre, low in fat and rich in vitamins and minerals. People who don't eat breakfast regularly are much more likely to have diets that are nutritionally inadequate and are less likely to meet national dietary targets for cereal and fibre intakes. The breakfast meal appears to be particularly important for older adults, providing a higher proportion of their total daily intake of nutrients compared to younger people. Those who include breakfast cereal also are more likely to have diets that meet recommended dietary intakes, however the extent to which breakfast eating itself, or other lifestyle habits of regular breakfast eaters, leads to better health is unclear.

\section{Acknowledgments}

Kellogg (Aust) Pty Ltd commissioned the analysis of the NNS data by staff of the Australian Bureau of Statistics. I would like to thank Chris Ryan, Tony Lloyd, Kate Wright and Dale Wallace of the Australian Bureau of Statistics for undertaking the detailed analyses. 
Table 1. Median nutrient intake of Australian adult males from breakfast and the percentage contribution to total daily intake

\begin{tabular}{|c|c|c|c|c|c|c|c|c|c|c|c|c|}
\hline & \multicolumn{3}{|c|}{$19-24 y$} & \multicolumn{3}{|c|}{$25-44 y$} & \multicolumn{3}{|c|}{$45-64 y$} & \multicolumn{3}{|c|}{$65+y$} \\
\hline & Media & $n \quad S E$ & $\%$ & Medic & $n S E$ & $\%$ & Medic & an $S E$ & $\%$ & Media & $n \quad S E$ & $\%$ \\
\hline Energy (kJ) & 1629 & 81 & 12.7 & 1400 & 60 & 12.6 & 1537 & 28 & 15.6 & 1733 & 41 & 20.9 \\
\hline Protein (g) & 12.4 & 1.3 & 10.4 & 11.5 & 0.6 & 10.9 & 13.8 & 0.3 & 14.1 & 14.5 & 0.4 & 18.1 \\
\hline Fat $(\mathrm{g})$ & 9.8 & 0.7 & 8.8 & 8.1 & 0.4 & 8.4 & 9.6 & 0.5 & 11.4 & 10.5 & 0.4 & 15.3 \\
\hline Carbohydrate (g) & 53.2 & 3.8 & 15.0 & 47.8 & 1.5 & 16.1 & 53.1 & 1.3 & 20.1 & 60.8 & 2.0 & 26.5 \\
\hline Sugar (g) & 18.0 & 2.9 & 11.2 & 18.0 & 2.9 & 14.6 & 20.0 & 0.6 & 18.5 & 28.2 & 0.9 & 26.7 \\
\hline Dietary Fibre (g) & 2.4 & 0.3 & 10.0 & 2.9 & 0.1 & 12.2 & 4.1 & 0.2 & 16.7 & 5.3 & 0.2 & 23.5 \\
\hline Thiamin (mg) & 0.52 & 0.05 & 26.0 & 0.40 & 0.03 & 23.5 & 0.45 & 0.02 & 28.1 & 0.50 & 0.02 & 35.7 \\
\hline Riboflavin (mg) & 0.55 & 0.08 & 22.9 & 0.41 & 0.05 & 19.5 & 0.54 & 0.02 & 27.0 & 0.68 & 0.04 & 37.8 \\
\hline Niacin (mg) & 7.95 & 0.49 & 14.7 & 6.72 & 0.25 & 13.5 & 7.67 & 0.23 & 16.4 & 7.58 & 0.23 & 20.5 \\
\hline Folate $(\mu \mathrm{g})$ & 41.4 & 4.0 & 13.6 & 36.4 & 1.5 & 12.8 & 47.3 & 1.6 & 16.1 & 55.5 & 2.1 & 21.6 \\
\hline Vitamin A (RE) & 94.5 & 7.1 & 9.0 & 75.2 & 4.4 & 8.3 & 92.9 & 3.8 & 9.8 & 99.4 & 4.5 & 10.7 \\
\hline Vitamin C (mg) & 2.5 & 0.3 & 2.6 & 1.5 & 0.2 & 1.5 & 2.0 & 0.2 & 1.8 & 3.0 & 0.2 & 2.8 \\
\hline Calcium (mg) & 161 & 16 & 16.7 & 145 & 7 & 16.5 & 185 & 10 & 23.4 & 227 & 8 & 31.0 \\
\hline Iron (mg) & 2.0 & 0.20 & 11.8 & 2.2 & 0.13 & 14.5 & 3.1 & 0.11 & 20.3 & 3.5 & 0.10 & 25.5 \\
\hline Magnesium (mg) & 52.0 & 4.4 & 14.3 & 54.0 & 2.0 & 14.7 & 69.3 & 2.8 & 18.8 & 82.2 & 2.3 & 25.4 \\
\hline Zinc (mg) & 1.4 & 0.14 & 9.3 & 1.4 & 0.07 & 10.6 & 1.7 & 0.05 & 13.6 & 1.9 & 0.07 & 13.9 \\
\hline Phosphorus (mg) & 250 & 22 & 13.3 & 234 & 12 & 13.5 & 301 & 10 & 18.7 & 326 & 11 & 24.2 \\
\hline Potassium (mg) & 428 & 44 & 11.7 & 425 & 17 & 11.9 & 514 & 16 & 14.3 & 604 & 25 & 19.6 \\
\hline
\end{tabular}


Table 2 Median nutrient intakes of Australian adult females from breakfast and the percentage contribution to total daily intake

\begin{tabular}{|c|c|c|c|c|c|c|c|c|c|c|c|c|}
\hline & \multicolumn{3}{|c|}{$19-24 y$} & \multicolumn{3}{|c|}{$25-44 y$} & \multicolumn{3}{|c|}{$45-54 y$} & \multicolumn{3}{|c|}{$55+y$} \\
\hline & Medic & $n \quad S E$ & $\%$ & Medi & an $S E$ & $\%$ & Medi & an $S E$ & $\%$ & Medi & an $S E$ & $\%$ \\
\hline Energy (kJ) & 1051 & 43 & 13.3 & 1056 & 27 & 14.0 & 1099 & 24 & 15.8 & 1211 & 20 & 19.8 \\
\hline Protein $(\mathrm{g})$ & 8.6 & 0.7 & 11.7 & 8.8 & 0.2 & 12.3 & 9.5 & 0.4 & 13.6 & 10.8 & 0.2 & 17.7 \\
\hline Fat $(\mathrm{g})$ & 5.5 & 0.6 & 8.2 & 5.9 & 0.2 & 8.9 & 5.5 & 0.2 & 9.2 & 6.8 & 0.2 & 13.3 \\
\hline Carbohydrate (g) & 37.9 & 2.2 & 16.6 & 37.2 & 0.8 & 17.7 & 39.2 & 1.0 & 20.7 & 43.0 & 0.8 & 25.0 \\
\hline Sugar (g) & 13.9 & 1.4 & 13.0 & 13.3 & 0.7 & 14.9 & 15.2 & 0.9 & 18.4 & 18.6 & 0.5 & 23.0 \\
\hline Dietary Fibre (g) & 2.0 & 0.2 & 11.5 & 2.7 & 0.1 & 14.6 & 2.3 & 0.2 & 11.5 & 4.2 & 0.1 & 21.8 \\
\hline Thiamin (mg) & 0.26 & 0.03 & 21.6 & 0.28 & 0.01 & 23.3 & 0.34 & 0.02 & 28.3 & 0.38 & 0.01 & 34.5 \\
\hline Riboflavin (mg) & 0.34 & 0.06 & 22.7 & 0.32 & 0.03 & 21.3 & 0.41 & 0.03 & 25.6 & 0.53 & 0.02 & 35.3 \\
\hline Niacin (mg) & 4.43 & 0.37 & 13.4 & 5.11 & 0.13 & 15.2 & 5.43 & 0.23 & 16.6 & 5.92 & 0.17 & 20.9 \\
\hline Folate $(\mu \mathrm{g})$ & 27.7 & 2.5 & 12.8 & 32.2 & 0.8 & 15.3 & 35.6 & 1.9 & 15.7 & 45.6 & 1.2 & 20.9 \\
\hline Vitamin A (RE) & 49.8 & 5.6 & 6.7 & 55.8 & 2.7 & 7.8 & 50.8 & 2.9 & 6.3 & 70.2 & 2.8 & 8.9 \\
\hline Vitamin C (mg) & 1.3 & 0.2 & 1.8 & 1.3 & 0.1 & 1.7 & 1.5 & 0.1 & 1.6 & 2.6 & 0.1 & 2.8 \\
\hline Calcium (mg) & 115 & 14 & 16.9 & 121 & 5 & 16.9 & 147 & 7 & 21.2 & 189 & 6 & 30.5 \\
\hline Iron (mg) & 1.5 & 0.17 & 14.1 & 1.8 & 0.07 & 16.2 & 2.3 & 0.09 & 19.8 & 2.7 & 0.07 & 25.0 \\
\hline Magnesium (mg) & 40.0 & 3.3 & 16.2 & 46.1 & 1.3 & 17.3 & 54.4 & 3.0 & 19.3 & 69.5 & 2.0 & 26.9 \\
\hline Zinc (mg) & 1.0 & 0.09 & 11.1 & 1.1 & 0.05 & 12.2 & 1.2 & 0.06 & 13.3 & 1.5 & 0.04 & 19.0 \\
\hline Phosphorus (mg) & 168 & 14 & 13.7 & 179 & 7 & 14.6 & 211 & 13 & 17.1 & 258 & 6 & 24.0 \\
\hline Potassium (mg) & 331 & 39 & 13.1 & 357 & 12 & 13.3 & 408 & 19 & 14.5 & 483 & 11 & 18.6 \\
\hline
\end{tabular}


Table 3: Percentage of RDI ${ }^{(a)}$ or dietary target ${ }^{(\mathrm{b})}$ obtained from breakfast

\begin{tabular}{|c|c|c|c|c|c|c|c|c|c|c|}
\hline & \multicolumn{2}{|c|}{$19-24 y$} & \multicolumn{2}{|c|}{$25-44 y$} & \multirow{2}{*}{$\begin{array}{r}45-64 y \\
\text { males }\end{array}$} & \multirow{2}{*}{$\begin{array}{c}45-54 y \\
\text { females }\end{array}$} & \multirow{2}{*}{$\begin{array}{r}65+y \\
\text { males }\end{array}$} & \multirow{2}{*}{$\begin{array}{r}55+y \\
\text { females }\end{array}$} & \multicolumn{2}{|c|}{ All adults 19+y } \\
\hline & males & females & males & females & & & & & males & females \\
\hline Protein & 28.7 & 23.4 & 26.0 & 23.3 & 27.2 & 24.2 & 28.4 & 26.6 & 27.1 & 24.8 \\
\hline Dietary Fibre $^{\text {(a) }}$ & 14.3 & 11.6 & 16.1 & 12.8 & 19.1 & 15.5 & 22.7 & 18.6 & 17.7 & 15.9 \\
\hline Thiamin & 66.2 & 59.6 & 54.1 & 54.1 & 51.3 & 53.0 & 69.2 & 67.5 & 57.1 & 56.3 \\
\hline Riboflavin & 58.7 & 54.4 & 47.9 & 49.6 & 44.0 & 48.1 & 64.9 & 64.9 & 54.0 & 55.2 \\
\hline Niacin equivalents & 50.2 & 48.2 & 44.8 & 47.9 & 44.1 & 48.3 & 53.9 & 61.3 & 46.7 & 53.7 \\
\hline Folate & 27.6 & 20.8 & 24.9 & 20.9 & 28.2 & 23.1 & 28.2 & 26.7 & 26.7 & 23.7 \\
\hline Retinol equivalents & 32.7 & 16.4 & 22.8 & 15.4 & 21.3 & 13.3 & 22.8 & 16.3 & 26.5 & 15.6 \\
\hline Vitamin C & 70.3 & 61.2 & 48.4 & 56.7 & 49.3 & 58.3 & 52.9 & 67.2 & 53.3 & 61.9 \\
\hline Calcium & 34.3 & 23.3 & 29.9 & 23.0 & 29.8 & 25.0 & 34.3 & 22.1 & 31.1 & 22.9 \\
\hline Iron & 57.5 & 19.8 & 54.8 & 20.6 & 57.1 & 21.8 & 62.4 & 55.7 & 57.0 & 35.8 \\
\hline Magnesium & 22.6 & 20.3 & 23.5 & 22.1 & 26.9 & 25.9 & 31.3 & 30.9 & 25.5 & 26.4 \\
\hline Zinc & 16.0 & 10.6 & 14.9 & 11.1 & 16.0 & 12.0 & 18.1 & 14.4 & 15.7 & 11.5 \\
\hline Phosphorus & 34.4 & 23.6 & 31.8 & 23.6 & 33.4 & 26.1 & 37.4 & 30.0 & 33.4 & 26.7 \\
\hline
\end{tabular}

(a) Recommended Dietary Intake (National Health and Medical Research Council, 1991)

(b) Target for dietary fibre: $30 \mathrm{~g} /$ day (Better Health Commission, 1986) 
Table 4: Comparison of the mean daily nutrient intakes of Australian adult breakfast eaters and skippers ${ }^{\dagger}$

\begin{tabular}{|c|c|c|c|c|c|c|}
\hline & \multicolumn{3}{|c|}{$\begin{array}{c}\text { All males } \\
19+y\end{array}$} & \multicolumn{3}{|c|}{$\begin{array}{c}\text { All females } \\
19+y\end{array}$} \\
\hline & Eaters & Skippers & $P=$ & Eaters & Skippers & $P=$ \\
\hline Energy (kJ) & 11193 & 10453 & 0.001 & 7405 & 6814 & 0.001 \\
\hline Protein $(\mathrm{g})$ & 110 & 104 & 0.000 & 74 & 66 & 0.029 \\
\hline Fat $(\mathrm{g})$ & 99 & 95 & 0.231 & 66 & 64 & 0.138 \\
\hline Carbohydrate (g) & 310 & 266 & 0.001 & 210 & 184 & 0.022 \\
\hline Sugar $(g)$ & 139 & 121 & 0.060 & 96.6 & 85.1 & 0.078 \\
\hline Dietary Fibre (g) & 27.5 & 20.8 & 0.000 & 21.3 & 15.5 & 0.000 \\
\hline Thiamin (mg) & 2.1 & 1.6 & 0.000 & 1.4 & 1.0 & 0.000 \\
\hline Riboflavin (mg) & 2.3 & 1.7 & 0.000 & 1.9 & 1.3 & 0.000 \\
\hline Niacin (mg) & 51.4 & 48.1 & 0.020 & 34.2 & 29.7 & 0.001 \\
\hline Folate $(\mu \mathrm{g})$ & 319 & 272 & 0.005 & 242 & 186 & 0.000 \\
\hline Vitamin A (RE) & 1360 & 1181 & 0.050 & 1083 & 1166 & 0.033 \\
\hline Vitamin C (mg) & 144 & 113 & 0.000 & 120 & 84 & 0.000 \\
\hline Calcium (mg) & 993 & 792 & 0.000 & 768 & 614 & 0.000 \\
\hline Iron (mg) & 17.2 & 13.8 & 0.000 & 12.3 & 9.3 & 0.000 \\
\hline Magnesium (mg) & 396 & 332 & 0.000 & 292 & 232 & 0.000 \\
\hline Zinc (mg) & 14.4 & 14.0 & 0.076 & 9.9 & 8.4 & 0.030 \\
\hline Phosphorus (mg) & 1824 & 1593 & 0.001 & 1289 & 1079 & 0.000 \\
\hline Potassium (mg) & 3821 & 3381 & 0.005 & 2884 & 2331 & 0.000 \\
\hline
\end{tabular}

${ }^{\dagger}$ Eaters had breakfast five or more days/week; Skippers ate breakfast rarely or never 
Table 5. Breakfast eating and self-reported health status of adults

(Percentage of breakfast eaters and skippers)

\begin{tabular}{|c|c|c|c|}
\hline Health Status & Eaters & Skippers & P = \\
\hline Excellent & 19.8 & 16.4 & 0.002 \\
\hline Very Good & 37.5 & 36.5 & 0.468 \\
\hline Good & 27.2 & 31.4 & 0.015 \\
\hline Fair & 12.0 & 12.7 & 0.388 \\
\hline Poor & 3.6 & 3.1 & 0.340 \\
\hline
\end{tabular}


Figure 1. Percentage of adult females meeting the RDI of selected vitamins and minerals, comparing breakfast Eaters (E) and Skippers (S)

Figure 2. Percentage of adult males meeting the RDI of selected vitamins and minerals, comparing breakfast Eaters (E) and Skippers (S)

Figure 3. Breakfast eating and \% adults not meeting 70\% RDI 


\section{References}

Australia New Zealand Food Authority (1999). AUSNUT - Australian Food and Nutrient Database. Canberra, ANZFA.

Belloc N \& Breslow L (1972). Relationship of physical health status and health practices. Preventive Medicine 1, 409-421.

Benton D \& Parker P (1998). Breakfast, blood glucose, and cognition. American Journal of Clinical Nutrition 67(suppl), 772S-778S.

Better Health Commission (1986). Looking forward to better health. Vol 2. The taskforces and working groups: reports to the Better Health Commission. Canberra, AGPS.

Cashel K \& Jeffreson S (1995). The Core Food Groups. The scientific basis for developing nutrition education tools. Canberra, NH\&MRC.

Chao S \& Vanderkooy P (1989). An overview of breakfast nutrition. Journal of the Canadian Dietetic Association 50, 225-258.

Clay W (1997). Preparation and use of food-based dietary guidelines. Food, Nutrition and Agriculture 19, 42-45.

Food Standards Australia New Zealand (2002). Food Standards Code - Volume 2. Canberra, Information Australia.

Galvin M, Kiely M \& Flynn A (2003). Impact of ready-to-eat breakfast cereal (RTEBC) consumption on adequacy of micronutrient intakes and compliance with dietary recommendations in Irish adults. Public Health Nutrition 6, 351363.

Hackett A, Rugg-Gunn A, Appleton D \& Coombs A (1986). Dietary sources of energy, protein, fat and fibre in 375 English adolescents. Human Nutrition: Applied Nutrition 40A, 176-184.

Huang Y, Hoerr S \& Song W (1997). Breakfast is the lowest fat meal for young adult women. Journal of Nutrition Education 29, 184-188.

Kanarek R (1997). Psychological effects of snacks and altered meal frequency. British Journal of Nutrition 77 (Suppl1), S105-S120.

Kaplan G, Seeman T, Cohen R, Knudsen L \& Guralnik J (1987). Mortality among the elderly in the Almeda County Study: behavioural and demographic risk factors. American Journal of Public Health 77, 307-312.

Keski-Rahkonen A, Kaprio J, Rissanen A, Vikkunen M \& Rose R (2003). Breakfast skipping and health-compromising behaviors in adolescents and adults. European Journal of Clinical Nutrition 57, 842-53.

Kirk T, Burskill S \& Cursiter M (1997). Dietary fat reduction achieved by increasing consumption of a starch food - an intervention study. European Journal of Clinical Nutrition 51, 455-461.

Liu S, Sesso H, Manson J, Willett W \& Buring J (2003). Is intake of breakfast cereals related to total and cause-specific mortality in men? American Journal of Clinical Nutrition 77, 594-599.

MacDiarmid J, Hamilton V, Cade J \& Blundell E (1997). Leeds High Fat Study: Behavioural characterization of high and low fat consumers. Proceedings of the Nutrition Society 56, 52A. 
Mattes R (2002). Ready-to-eat cereal used as a meal replacement promotes weight loss in humans. Journal of the American College of Nutrition 21, 570-577.

McLennan W \& Podger A (1997). National Nutrition Survey. Selected Highlights 1995. ABS Cat No 4802.0. Canberra, Australian Bureau of Statistics.

McLennan W \& Podger A (1998). National Nutrition Survey Users' Guide 1995. ABS Cat No 4801.0. Canberra, Australian Bureau of Statistics.

McLennan W \& Podger A (1998). National Nutrition Survey. Nutrient intakes and physical measurements. ABS Cat No 4805.0. Canberra, Australian Bureau of Statistics.

McLennan W \& Podger A (1999). National Nutrition Survey. Food Eaten. Australia 1995. ABS Cat No 4804.0. Canberra, Australian Bureau of Statistics.

McNulty H, Eaton-Evans J, Woulahan G \& Strain J (1994). The contribution of breakfast to daily micronutrient intakes of adults in Great Britain. Proceedings of the Nutrition Society 53, 251A.

Michaud C, Musse N, Nicolas J \& Mejean L (1991). Effects of breakfast size on shortterm memory, concentration, mood and blood glucose. Journal of Adolescent Health 12, 53-57.

Morgan K, Zabik M \& Leveille G (1981). The role of breakfast in nutrient intake of 5 to 12 year-old children. American Journal of Clinical Nutrition 34, 1418-1427.

Morgan K, Zabik M \& Stampley G (1986). The role of breakfast in the diet adequacy of the US adult population. Journal of the American College of Nutrition 5, 551-563.

Morgan K, Zabik M \& Stampley G (1996). Breakfast consumption patterns of older Americans. Journal of Nutrition for the Elderly 5, 19-44.

National Health and Medical Research Council (1991). Recommended Dietary Intakes for Use in Australia. Canberra, NH\&MRC.

National Health and Medical Research Council (1999). Dietary Guidelines for Older Australians. Canberra, Australian Government Publishing Service.

Preziosi P, Galan P, Deheeger M, Yacoub N, Drenowski A \& Hercberg S (1999). Breakfast type, daily nutrient intakes and vitamin and mineral status of French children, adolescents and adults. Journal of the American College of Nutrition 18, 171-178.

Reger C, Nicklas T, Myers L, Beech B \& Berenson G (1997). Does breakfast consumption affect nutritional adequacy of the diets of young adults? Journal of the American Dietetic Association 97(Suppl), A89.

Ruxton C \& Kirk T (1997). Breakfast: a review of associations with measures of dietary intake, physiology and biochemistry. British Journal of Nutrition 78, 199-213.

Schmidt T, Carden-Robinson J, North B \& Nicklas T (1998). Impact of breakfast consumption and RTE cereals on nutritional adequacy of the diets of young adults in Bogalusa, LA: ethnic and gender contrast. Journal of the American Dietetic Association 98(Suppl), A68.

Siega-Riz A, Popkin B \& Carson T (1998). Trends in breakfast consumption for children in the United States from 1865 to 1991. American Journal of Clinical Nutrition 67(suppl), 748S-756S.

Smith A (1998). Breakfast and mental health. International Journal of Food Sciences 
and Nutrition 49, 397-402.

Smith A (1999). Breakfast cereal consumption and subjective reports of health. International Journal of Food Sciences and Nutrition 50, 445-449.

Sommerville J \& O'Reagan M (1993). The contribution of breakfast to micronutrient adequacy of the Irish diet. Journal of Human Nutrition and Dietetics 6, 223228.

Stanton J \& Keast D (1989). Serum cholesterol, fat intake, and breakfast consumption in the United States adult population. Journal of the American College of Nutrition 8, 567-572.

Syrette J, Baghurst K \& Record S (1990). Breakfast cereals - patterns of consumption and nutritional value of regular usage. Food Australia 42, 568-573.

Wang Y, Reilly C, Patterson C, Morrison E \& Tinggi U (1992). Contribution of breakfast cereals to Australian intake of trace elements. Food Australia 44, 7072.

Williams P (1998). The contribution of breakfast to the nutrition of Australians. Proceedings of the Kellogg Nutrition Symposium, Sydney, Kellogg (Aust) Pty Ltd.

Williams P (2002). What Australians eat for breakfast: an analysis of data from the 1995 National Nutrition Survey. Nutrition and Dietetics 59, 103-112.

World Health Organization (1998). Carbohydrates in human nutrition: a report of a joint FAO/WHO expert consultation. FAO Food and Nutrition Paper No66. Rome, Food and Agriculture Organization.

Wyatt H, Grunwald G, Mosca C, Klem M, Wing R \& Hill J (2002). Long-term weight loss and breakfast in subjects in the National Weight Control Registry. Obesity Research 10, 78-82.

Zabik M (1987). Impact of ready-to-eat cereal consumption on nutrient intake. Cereal Foods World 32, 234-239. 